\section{Sesquiterpene Lactones and Bitterness in Korean Leaf Lettuce Cultivars}

\author{
Myeong Whoon Seo \\ Division of Horticulture Research, Gyeonggi-do Agricultural Research and \\ Extension Service, Hwaseong 445-972, Korea
}

Dong Sik Yang

Institute of Life Science \& Natural Resources, Korea University, Seoul 136713, Korea

Stanley J. Kays
Department of Horticultural Science, The University of Georgia, Athens, GA
30602-7273

Gung Pyo Lee

Department of Applied Plant Science, Chung-Ang University, Ansung 456756, Korea

\section{Kuen Woo Park ${ }^{1}$ \\ Division of Biotechnology, College of Life Sciences and Biotechnology, Korea University, Seoul 136-701, Korea}

Additional index words. lactucin, 8-deoxylactucin, lactucopicrin, bitter activity value, bitterness threshold

\begin{abstract}
The principal bitter sesquiterpene lactones (BSLs; latucin, 8-deoxylactucin, and lactucopicrin) in six red and four green-pigmented leaf lettuce (Lactuca sativa L. var. crispa L.) cultivars were identified and quantified using high-performance liquid chromatography, proton nuclear magnetic resonance, and liquid chromatography-mass spectrometry and the contribution of each to the overall bitterness was determined. The concentration of each BSL and the total varied significantly among cultivars and there were significant differences resulting from leaf color (green versus red) and morphology (cut versus curled leaves) with red and curled leaf cultivars having higher BSL concentrations. The concentrations of lactucin, 8-deoxylactucin, and lactucopicrin ranged from 2.9 to $17.2,2.8$ to 17.1 , and 8.8 to $36.1 \mu \mathrm{g} \cdot \mathrm{g}^{-1}$ dry weight, respectively, with the total concentration ranging from 14.6 to $67.7 \mu \mathrm{g} \cdot \mathrm{g}^{-1}$. Bitterness of the cultivars was assessed using a bitter activity value calculated using the concentration and bitterness threshold value for each BSL. Lactucopicrin was the primary contributor to bitterness as a result of its concentration and lower bitterness threshold; its relative proportion of the total bitterness activity value across all cultivars was over $72 \%$. The concentration of individual BSLs differed with leaf location on the plant (i.e., basal, midstalk, and flower stalk). The concentrations in lactucin, 8-deoxylactucin, and lactucopicrin in flower stalk leaves were significantly higher (i.e., 2.9, 12.4, and 5.4 times, respectively) than in basal leaves, with the concentrations increasing acropetally. Genetic differences among cultivars and with leaf location on the plant contribute to the wide range in bitterness in lettuce.
\end{abstract}

Lettuce (Lactuca sativa L.) is the leading leafy vegetable worldwide with an estimated annual production of $23 \times 10^{6} \mathrm{t}$ in 2007 (Food Agriculture Organization of the United Nations, 2007). The most widely used lettuce types are classified into the following groups: butternut (head or cabbage), $\cos$ ( $\cos$ or romaine), cutting (curled or leaf), and stalk (asparagus or stem) (Mansfeld, 2008). Over the past 7 years, the production of leaf and

Received for publication 18 Sept. 2008. Accepted for publication 30 Nov. 2008.

This research was partially supported by the Chung-Ang University Excellent Researcher Grant in 2007.

${ }^{1}$ To whom reprint requests should be addressed; e-mailkuenwp@korea.ac.kr. bitter sesquiterpene lactones (BSLs) in lettuce and chicory (Cichorium intybus L.) are lactucin, 8-deoxylactucin, and lactucopicrin (Price et al., 1990; Tamaki et al., 1995; Van Beek et al., 1990). Their impact on taste is the result of their concentrations and low bitter thresholds (Van Beek et al., 1990). In lettuce and chicory, BSL concentrations are known to vary among cultivars (Price et al., 1990), e.g., the concentrations of lactucin-like sesquiterpene lactones and lactucopicrin in 13 chicory root cultivars ranged from 136 to 310 and 62 to $254 \mathrm{mg} \cdot \mathrm{kg}^{-1}$ fresh weight, respectively (Peters et al., 1997). As a result of their bitterness, when the concentration is sufficiently high in chicory, consumer preference is markedly reduced (Drewnowski and Gomez-Carneros, 2000). Differences in sesquiterpene lactones in lettuce can also strongly modulate taste and consumer acceptance (Hance et al., 2007). As a result of the importance of these compounds in consumer acceptance and plant breeding, the composition of BSLs was measured and their contribution to bitterness determined in 10 popular Korean leaf lettuce cultivars.

\section{Materials and Methods}

Plant material. Ten leaf lettuce cultivars (four green- and six red-leafed) that are popular in Korea (Table 1) were grown in the Gyeonggi-do Agricultural Research and Extension Services greenhouses (long. $36^{\circ} \mathrm{N}$, lat. $\left.126^{\circ} \mathrm{E}\right)$, Hwasung, South Korea, in 2001. The cultivars were seeded 8 June on a urethane sponge and the seedlings transplanted to a deep flow culture system 29 June arranged in a randomized block design with three replications of 10 plants. During growth, Yamazaki nutrient solution for lettuce was used (Yamazaki, 1982). The concentrations of macronutrients $\left(\mathrm{NO}_{3}-\mathrm{N}, \mathrm{NH}_{4}-\mathrm{N}, \mathrm{PO}_{4}-\mathrm{P}\right.$, potassium, calcium, magnesium, and $\mathrm{SO}_{4}-\mathrm{S}$ ) were $6,0.5,0.5,4,1,0.5$, and $0.5 \mathrm{~mm}$, respectively, and the concentrations of micronutrients (iron, boron, manganese, zinc, copper, and molybdenum) were $35,18,3.6,0.3,0.2$, and $0.1 \mu \mathrm{M}$, respectively. The electrical conductivity and $\mathrm{pH}$ of the solution were measured daily and the nutrient solution replaced weekly. The plant leaf samples were harvested on 23 Aug. To test the effect of leaf location on the plant, basal leaves were also collected on 6 Sept. and midstalk and flower stalk leaves collected 12 Oct. Harvest dates were varied to allow for obtaining leaves of similar quality at each position on the plant. Midstalk samples were harvested from between leaves 15 and 20 from the base of the plant and flower stalk samples from between leaves 50 and 55 from the bottom. The samples were mixed, placed in vinyl freezer bags, and held at $-80^{\circ} \mathrm{C}$. The frozen samples were subsequently lyophilized for $48 \mathrm{~h}$ using a vacuum freeze-drier (PVTFD100A; Ilshin Laboratory Co., Yangju, Korea). The freeze-dried samples were ground to a fine powder using a mortar and pestle and held at $-80{ }^{\circ} \mathrm{C}$ until analysis. Chlorophyll content was estimated using SPAD units (leaf 
Table 1. List and characteristics of different leaf lettuce cultivars.

\begin{tabular}{lllcl}
\hline Cultivar & Seed company & Code & Leaf color & Leaf type \\
\hline Ganghancheongchima & Dongbu Hannong & GGL & Green & Cut leaf \\
Cheonghacheongchima & Asia Seeds & CGL & Green & Cut leaf \\
Hanbatcheongchima & Nongwoo Bio & HGL & Green & Cut leaf \\
Hajicheongchukmyeon & Hungnong Seeds & JGC & Green & Curled leaf \\
Daetongyeoleumjeokchukmyeon & Daenong Seeds & DRC & Red & Curled leaf \\
Seonpungpochapjeokchukmyeon & Kwonnong Seeds & SRC & Red & Curled leaf \\
Taepungyeoleumjeokchukmyeon & Kwonnong Seeds & TRC & Red & Curled leaf \\
Yeonsanhongjeokchukmyeon & Nongwoo Bio & YRC & Red & Curled leaf \\
Waolhajeokchukmyeon & Novartis & WRC & Red & Curled leaf \\
Bulkkotchukmyeon & Joonang Seeds & BRC & Red & Curled leaf \\
\hline
\end{tabular}

chlorophyll index) obtained with a SPAD502 chlorophyll meter (Konica Minolta Sensing Inc., Osaka, Japan), and sugar content was determined using a PR32 refractometer (Atago Co., Tokyo, Japan).

Isolation of bitter sesquiterpene lactones. The samples were analyzed using the method of Price et al. (1990) in which powdered lyophilized aliquots $(1 \mathrm{~g})$ were extracted with $100 \mathrm{~mL}$ of methanol by boiling under reflux at $65^{\circ} \mathrm{C}$ for $1 \mathrm{~h}$ and filtered through Whatman \#2 filter paper. The methanol was evaporated under reduced pressure in a rotary evaporator $\left(\approx 5 \mathrm{~mm} \mathrm{Hg}, 30\right.$ to $\left.35^{\circ} \mathrm{C}\right)$. The sesquiterpene lactone santonin $(50 \mu \mathrm{g})$ was added as an internal standard to the crude extract as a result of its similar structure $\left(\mathrm{C}_{15} \mathrm{H}_{18} \mathrm{O}_{3}\right)$ and molecular weight (246.29) to two of the BSLs [lactucin $\left(\mathrm{C}_{15} \mathrm{H}_{16} \mathrm{O}_{5}, 276.3\right)$, 8-deoxylactucin $\left(\mathrm{C}_{15} \mathrm{H}_{16} \mathrm{O}_{4}, 260.3\right)$, lactucopicrin $\left(\mathrm{C}_{23} \mathrm{H}_{22} \mathrm{O}_{7}\right.$, 410)]. The extract was then partitioned three times between water/chloroform $(200 \mathrm{~mL}$; 1:1 mixture by volume) with the chloroform separated, dried over anhydrous magnesium sulfate, and evaporated using a rotary evaporator $\left(\approx 5 \mathrm{~mm} \mathrm{Hg}, 20\right.$ to $\left.30{ }^{\circ} \mathrm{C}\right)$. The residue was dissolved in $0.5 \mathrm{~mL}$ methanol/chloroform (1:2 by volume) and the BSLs separated using high-performance liquid chromatography (HPLC) and monitored at $256 \mathrm{~nm}$.

High-performance liquid chromatography analysis. The bitter sesquiterpene lactones were separated using a HP 1100 series HPLC system (Hewlett-Packard Co., Palo Alto, CA) equipped with an AD 25 Absorbance Detector (Dionex Co., Sunnyvale, CA). A Luna $\mathrm{C}_{18}$ column $(250 \times 4.6 \mathrm{~mm}$ i.d., $5-\mu \mathrm{m}$ particles; Phenomenex Co., Torrance, CA) was used with a water/acetonitrile mobile phase at a flow rate of $1 \mathrm{~mL} / \mathrm{min}$. The solution gradient started at 90:10 (by volume) and was altered in a linear manner to a final ratio of 58:42 over $30 \mathrm{~min}$. The BSLs (i.e., lactucin, 8deoxylactucin, and lactucopicrin; Fig. 1) were monitored at $256 \mathrm{~nm}$.

Identification and quantification. BSLs were identified by proton nuclear magnetic resonance (NMR) (Avance DRX-600; Bruker Co., Karlsruhe, Germany) spectroscopy and quadrupole liquid chromatography-mass spectrometry (LC-MS) (Quattro LC; Micromass \& Water Co., Milford, MA). All spectra from ${ }^{1} \mathrm{H}$ NMR were recorded at $600 \mathrm{MHz}$ with $3 \mathrm{mg}$ of each compounds in $0.5 \mathrm{~mL} d_{4^{-}}$ $\mathrm{MeOH}$, and $20 \mu \mathrm{L}$ of $3 \mathrm{mg}$ in $100 \mathrm{~mL}$ methanol was injected for LC-MS. ${ }^{1} \mathrm{H}$ NMR and LC-MS spectra were compared with those reported in the literature (Song et al., 1995; Van Beek et al., 1990). Individual BSLs were quantified using HPLC $(20 \mu \mathrm{L}$ alents (Price et al., 1990). Three replications of each cultivar were analyzed.

Bitter activity value. Bitter activity values were calculated by dividing the concentration of each BSL by its bitter threshold in water as measured by Van Beek et al. (1990).

Statistical analysis. Analysis of variance and Duncan's multiple range test were carried out using the SAS system (SAS Institute, Inc., Cary, NC).

\section{Results and Discussion}

The concentration of each BSL and the total concentration varied widely among cultivars (Table 2). The cultivar effect was highly significant as was the effect for leaf color (i.e., green versus red) and morphology (i.e., cut versus curled leaves). In particular, the concentration of the BSL and the total in red-colored and curled leaf cultivars were significantly higher than green and cut leaf cultivars. The results substantiated the degree of genetic variation in BSLs within lettuce and chicory germplasm reported by Price et al. (1990). In addition, environmental (e.g., location, planting date) and postharvest (e.g., harvest date, temperature) factors are also known to affect the level of BSLs in injection) and expressed as santonin equivleaves. same letter within a column are not significantly different. forage chicory cultivars (Foster et al., 2006). The concentration of anthocyanin in redleafed cultivars also varied as a result of genetic and environmental factors (Gazula et al., 2007). Based on the existing evidence, the synthesis of anthocyanins and BSLs appeared to be related to some extent.

The total concentrations of the three BSLs ranged from 14.6 to $67.7 \mu \mathrm{g} \cdot \mathrm{g}^{-1}$ with an average concentration of $37.5 \mu \mathrm{g} \cdot \mathrm{g}^{-1}$. The cultivars could be separated into two general groups based on BSL concentration: 1) high [Bulkkotchukmyeon (BRC, $67.7 \mu \mathrm{g} \cdot \mathrm{g}^{-1}$ ), Hajicheongchukmyeon (JGC, 59.5), Yeonsanhongjeokchukmyeon (YRC, 55.1), Seonpungpochapjeokchukmyeon (SRC, 54.2)]; and 2) low [Cheonghacheongchima (CGL, 28.0), Waolhajeokchuknyeon (WRC, 26.8), Daetongyeoleumjeokchukmyeon (DRC, 25.6), Ganghancheongchima (GGL, 22.1), Taepungyeoleumjeokchukmyeon (TRC, 21.2), Hanbatcheongchima (HGL, 14.6)]. Lactucin concentrations ranged from 2.9 to $17.2 \mu \mathrm{g} \cdot \mathrm{g}^{-1}$ with an average concentration of $6.6 \mu \mathrm{g} \cdot \mathrm{g}^{-1}$. $\mathrm{BRC}$ had the highest concentration (17.2 $\mu \mathrm{g} \cdot \mathrm{g}^{-1}$ ) followed by $\operatorname{SRC}$ (7.4), JGC (7.2), YRC (6.8), WRC (6.6), and CGL (6.1). HGL and TRC had the lowest concentrations $(2.9$ and $\left.3.5 \mu \mathrm{g} \cdot \mathrm{g}^{-1}\right)$. The concentrations of 8 deoxylactucin ranged from 2.8 to $17.1 \mu \mathrm{g} \cdot \mathrm{g}^{-1}$ with an average concentration of $9.5 \mu \mathrm{g} \cdot \mathrm{g}^{-1}$. YRC, BRC, and JGC were significantly higher than the other cultivars. The concentration of lactucopicrin ranged from 8.8 to $36.1 \mu \mathrm{g} \cdot \mathrm{g}^{-1}$ with an average concentration of $21.4 \mu \mathrm{g} \cdot \mathrm{g}^{-1}$. JGC had the highest concentration $\left(36.1 \mu \mathrm{g} \cdot \mathrm{g}^{-1}\right)$ followed by SRC (34.3), BRC (33.7), and YRC (31.1). HGL was the lowest with only $8.8 \mu \mathrm{g} \cdot \mathrm{g}^{-1}$. When the three BSLs were combined, BRC had the highest total concentration and HGL the lowest. The concentration of 8-deoxylactucin was positively correlated with that of lactucopicrin $\left(r=0.9570^{* *}\right)$, whereas the correlations of lactucin with 8-deoxylactucin $\left(r=0.6976^{*}\right)$ and lactucopicrin $\left(r=0.6640^{*}\right)$ were significant but lower.

Table 2. The bitter sesquiterpene lactone (BSL) content in different cultivars of leaf lettuce.

\begin{tabular}{lcccc}
\hline & \multicolumn{4}{c}{ BSL contents $\left(\mu \mathrm{g} \cdot \mathrm{g}^{-1}\right.$ dry wt $)$} \\
\cline { 2 - 5 } Cultivar & Lactucin & 8-Deoxylactucin & Lactucopicrin & Total \\
\hline GGL & $4.4 \mathrm{~d}^{\mathrm{y}}$ & $5.1 \mathrm{~d}$ & $12.5 \mathrm{~cd}$ & $22.1 \mathrm{~cd}$ \\
CGL & $6.1 \mathrm{c}$ & $6.0 \mathrm{~cd}$ & $15.9 \mathrm{c}$ & $28.0 \mathrm{c}$ \\
HGL & $2.9 \mathrm{e}$ & $2.8 \mathrm{e}$ & $8.8 \mathrm{~d}$ & $14.6 \mathrm{e}$ \\
JGC & $7.2 \mathrm{~b}$ & $16.2 \mathrm{a}$ & $36.1 \mathrm{a}$ & $59.5 \mathrm{~b}$ \\
DRC & $3.6 \mathrm{de}$ & $7.2 \mathrm{c}$ & $14.8 \mathrm{c}$ & $25.6 \mathrm{~cd}$ \\
SRC & $7.4 \mathrm{~b}$ & $12.5 \mathrm{~b}$ & $34.3 \mathrm{ab}$ & $54.2 \mathrm{~b}$ \\
TRC & $3.5 \mathrm{e}$ & $4.9 \mathrm{~d}$ & $12.8 \mathrm{~cd}$ & $21.2 \mathrm{~d}$ \\
YRC & $6.8 \mathrm{bc}$ & $17.1 \mathrm{a}$ & $31.1 \mathrm{~b}$ & $55.1 \mathrm{~b}$ \\
WRC & $6.6 \mathrm{bc}$ & $6.4 \mathrm{~cd}$ & $13.8 \mathrm{c}$ & $26.8 \mathrm{~cd}$ \\
BRC & $17.2 \mathrm{a}$ & $16.8 \mathrm{a}$ & $33.7 \mathrm{ab}$ & $67.7 \mathrm{a}$ \\
Cultivar & $* * *$ & $* * *$ & $* * *$ & $* * *$ \\
Green $\times$ red color & $* *$ & $* * *$ & $* * *$ & $* * *$ \\
$\quad$ type & & & $* * *$ & $* *$ \\
Cut leaf $\times$ curled & NS & & & $* *$ \\
$\quad$ leaf & & &
\end{tabular}

${ }^{z}$ Cultivars correspond to the code given in Table 1; sampling time and leaf location: 23 Aug. 2001 and base

${ }^{y}$ Mean separation within columns by Duncan's multiple range test at $P \leq 0.05$. Means followed by the

NS, ${ }^{* *}, * * *=$ nonsignificant; significant at $P<0.01,0.001$, respectively. 
Table 3. Chlorophyll and sugar content of 10 leaf lettuce cultivars.

\begin{tabular}{lcc}
\hline Cultivar & $\begin{array}{c}\text { Chlorophyll } \\
\text { (SPAD units) }\end{array}$ & $\begin{array}{c}\text { Sugar content } \\
\text { ( }{ }^{\circ} \text { Brix) }\end{array}$ \\
\hline GGL & $26.8 \mathrm{a}^{\mathrm{y}}$ & $3.5 \mathrm{bc}$ \\
CGL & $26.3 \mathrm{a}$ & $3.1 \mathrm{c}$ \\
HGL & $27.3 \mathrm{a}$ & $3.5 \mathrm{bc}$ \\
JGC & $17.8 \mathrm{~b}$ & $3.9 \mathrm{bc}$ \\
DRC & $16.5 \mathrm{~b}$ & $4.7 \mathrm{~b}$ \\
SRC & $25.9 \mathrm{a}$ & $4.1 \mathrm{bc}$ \\
TRC & $26.9 \mathrm{a}$ & $4.2 \mathrm{bc}$ \\
YRC & $20.5 \mathrm{ab}$ & $3.7 \mathrm{bc}$ \\
WRC & $9.3 \mathrm{c}$ & $3.6 \mathrm{bc}$ \\
BRC & $7.3 \mathrm{c}$ & $6.2 \mathrm{a}$ \\
\hline
\end{tabular}

${ }^{\mathrm{z}}$ Cultivar corresponds to code in Table 1.

${ }^{y}$ Mean separation within columns by Duncan's multiple range test at $P \leq 0.05$. Means followed by the same letter within a column are not significantly different.

Before harvest, the chlorophyll and sugar contents in the leaves were measured. The chlorophyll contents of GGL, CGL, HGL, SRC, and TRC were significantly higher than the other cultivars; BRC had the lowest chlorophyll but the highest sugar content (Table 3). Lactucin concentration was significantly correlated with both leaf chlorophyll and sugar contents with correlation coefficient $(r)$ of $-0.6726^{*}$ and $0.7420^{*}$, respectively. Price et al. (1990) reported that the relationship between the level of lactucin and bitterness score was not significant $(r=$ 0.278); however, lactucin combined with sugar content significantly increased the relationship $(r=0.800)$ between the level of lactucin and bitterness. Correlations of 8 deoxylactucin and lactucopicrin with leaf chlorophyll and sugar contents were not significant. Therefore, chlorophyll and sugar contents in lettuce may influence lactucin concentration and subsequent bitterness.

The bitter activity values, obtained by dividing each BSL's concentration by its bitter threshold, were used to assess the relative importance of individual BSL and

Table 4. Bitterness of leaf lettuce cultivars based on bitter activity values.

\begin{tabular}{lcccc}
\hline & \multicolumn{4}{c}{ Bitter activity value $^{\mathrm{z}}$} \\
\cline { 2 - 5 } Cultivar $^{\mathrm{y}}$ & Lactucin & 8-Deoxylactucin & Lactucopicrin & Total \\
\hline GGL & 2.6 & 4.6 & 25.0 & $32.2 \mathrm{c}^{\mathrm{x}}$ \\
CGL & 3.6 & 5.5 & 31.8 & $40.8 \mathrm{c}$ \\
HGL & 1.7 & 2.5 & 17.6 & $21.9 \mathrm{~d}$ \\
JGC & 4.2 & 14.7 & 72.2 & $91.2 \mathrm{a}$ \\
DRC & 6.5 & 29.6 & $38.3 \mathrm{c}$ \\
SRC & 2.1 & 11.4 & 68.6 & $84.3 \mathrm{~b}$ \\
TRC & 4.4 & 4.5 & 25.6 & $32.1 \mathrm{c}$ \\
YRC & 2.1 & 15.5 & 62.2 & $81.7 \mathrm{~b}$ \\
WRC & 4.0 & 5.8 & 27.6 & $37.3 \mathrm{c}$ \\
BRC & 3.9 & 15.3 & 67.4 & $92.8 \mathrm{a}$ \\
\hline
\end{tabular}

${ }^{2}$ Bitter activity value is obtained by dividing the concentration of each bitter sesquiterpene lactone (see Table 2) by its bitterness threshold in water and means of three replicates per sample.

${ }^{y}$ Cultivar corresponds to code in Table 1.

${ }^{x}$ Means separation within a column by Duncan's multiple-range test at $P \leq 0.05$. The bitterness thresholds in water (lactucin, $1.7 \mu \mathrm{g} \cdot \mathrm{g}^{-1}$; 8 -deoxylactucin, $1.1 \mu \mathrm{g} \cdot \mathrm{g}^{-1}$; and lactucopicrin, $0.5 \mu \mathrm{g} \cdot \mathrm{g}^{-1}$ ) were reported by Van Beek et al. (1990).

Table 5. Bitter sesquiterpene lactone (BSL) content in leaves at different locations on the plant (cultivar Ganghancheongchima).

\begin{tabular}{lcccr}
\hline & \multicolumn{4}{c}{ BSL contents $\left(\mu \mathrm{g} \cdot \mathrm{g}^{-1} \mathrm{dwt}\right)$} \\
\cline { 2 - 5 } Plant part & Lactucin & 8-Deoxylactucin & Lactucopicrin & Total \\
\hline Basal leaves & $10.1 \mathrm{c}^{\mathrm{y}}$ & $2.9 \mathrm{c}$ & $20.8 \mathrm{c}$ & $33.8 \mathrm{c}$ \\
$\begin{array}{l}\text { Midstalk leaves } \\
\begin{array}{l}\text { Flower stalk } \\
\quad \text { leaves }\end{array}\end{array}$ & $13.2 \mathrm{~b}$ & $17.6 \mathrm{~b}$ & $30.9 \mathrm{~b}$ & $61.8 \mathrm{~b}$ \\
& $28.9 \mathrm{a}$ & $35.9 \mathrm{a}$ & $113.2 \mathrm{a}$ & $178.7 \mathrm{a}$ \\
\hline
\end{tabular}

${ }^{\mathrm{z}}$ Sampling time: basal leaves 6 Sept. 2001; mid (25th to 30th from bottom) and flower (50th to 55th from bottom) stalk leaves 12 Oct. 2001.

${ }^{y}$ Mean separation within columns by Duncan's multiple range test at $P \leq 0.05$. Means followed by the same letter within a column are not significantly different.

the overall bitterness (Table 4). The method is based on the principle of odor activity value that is commonly used for quantifying individual odors in aroma and flavor chemistry research (Reineccius, 2006). Based on data by Van Beek et al. (1990), the threshold values in water for lactucin, 8-deoxylactucin, and lactucopicrin were $1.7,1.1$, and $0.5 \mu \mathrm{g} \cdot \mathrm{g}^{-1}$. Lactucopicrin with the lowest threshold value is the most bitter of the three compounds. It comprised over $72 \%$ of the total of the three compounds of the bitterness activity value across cultivars. Lactucopicrin is the major contributor to bitterness in lettuce as a result of its concentration and low bitterness threshold and is also the primary contributor to bitterness in chicory (Foster et al., 2006). On the basis of bitterness activity values, BRC (92.8) and JGC (91.2) were the most bitter followed by SRC (84.3) and YRC (81.7). CGL (40.8), DRC (38.3), WRC (37.3), GGL (32.2), and TRC (32.1) were classified as having intermediate bitterness and HGL (21.9) was the least bitter. Leaf lettuce is

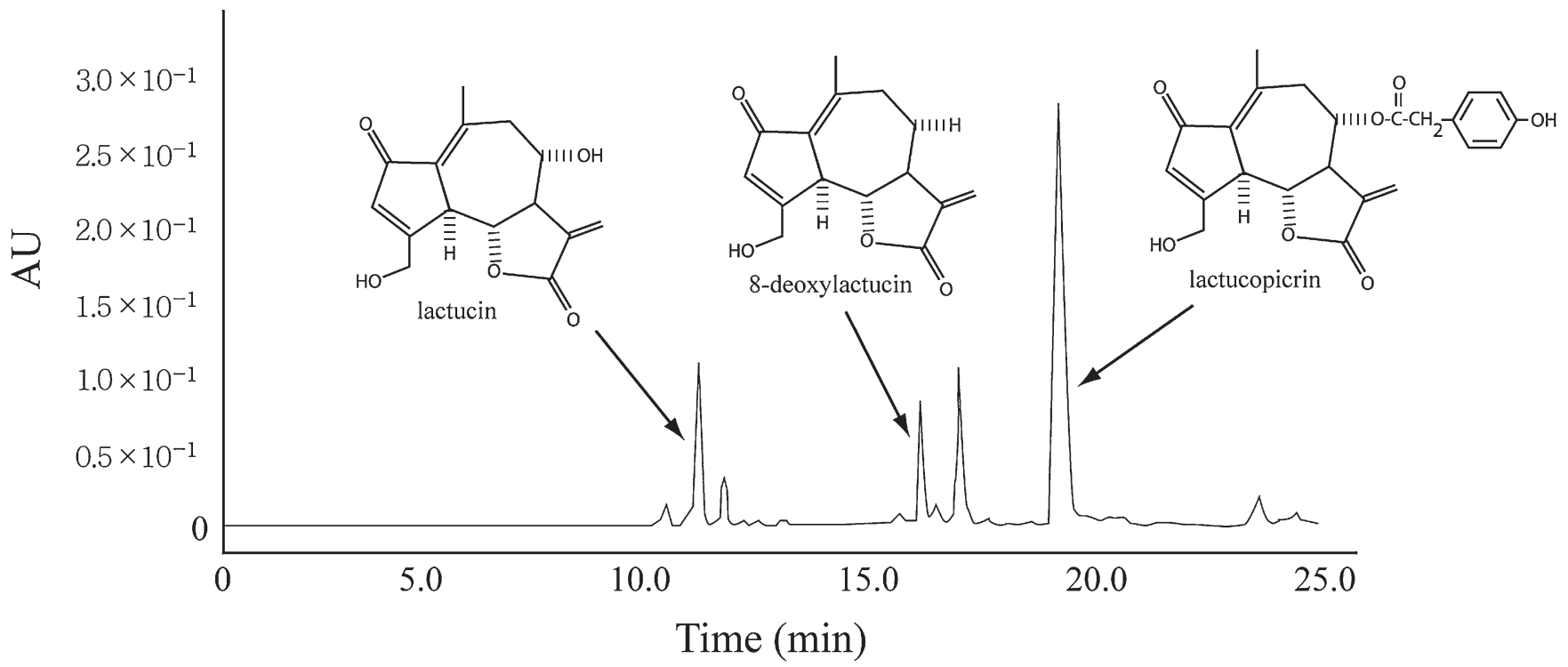

Fig. 1. High-performance liquid chromatography trace of the bitter sesquiterpene lactones in Korean leaf lettuce cultivars. 
generally considered to be more bitter than other types of lettuce (e.g., head, romaine) and bitterness in chicory and endive is two to three times higher than in lettuce (Price et al., 1990).

The concentration of BSLs varied with leaf position on the plant (Table 5). The BSL concentrations in basal, midstalk, and flower stalk leaves increased acropetally. For example, the concentrations of lactucin, 8-deoxylactucin, and lactucopicrin in flower stalk leaves were $28.9,35.9$, and $113.2 \mu \mathrm{g} \cdot \mathrm{g}^{-1}$, respectively. The concentration of individual and total BSLs in the basal and midstalk leaves were significantly lower; e.g., lactucin, 8-deoxylactucin, and lactucopicrin in flower stalk leaves were 2.9, 12.4, and 5.4 times higher than in the basal leaves. A similar finding has been reported for chicory in which the concentration in the storage root and the basal, midstem, and apical leaves were $0.42 \%, 0.22 \%, 0.26 \%$, and $0.34 \%$, respectively (Rees and Harborne, 1985). The leaf concentration, therefore, increases with position on the plant in an acropetal direction.

The concentration of the primary BSLs in lettuce (i.e., lactucin, 8-deoxylactucin, and lactucopicrin) varied quantitatively as a result of cultivar and leaf position on the plant. Among the three BSLs, lactucopicrin represents the best indicator of the overall bitterness of a lettuce cultivar as a result of its higher concentration and lower bitterness threshold value.

\section{Literature Cited}

Anonymous. 2007. National Agricultural Statistics Service. U.S. Dept. of Agr. Agricultural statistics database. 27 Aug. 2008. <http://www.nass.usda. gov/s.

Drewnowski, A. and C. Gomez-Carneros. 2000. Bitter taste, phytonutrients, and the consumer: A review. Am. J. Clin. Nutr. 72:1424-1435.

Food Agirculture Organization of the United Nations. 2007. FAO stat. 27 Aug. 2008. <http:// faostat.fao.org/site/567/default.aspx\#ancor>.

Foster, J.G., W.M. Clapham, D.P. Belesky, M. Labreveux, M.H. Hall, and M.A. Sanderson. 2006. Influence of cultivation site a sesquiterpene lactone composition of forage chicory (Cichorium intybus L.). J. Agr. Food Chem. 54:1772-1778.

Gazula, A., M.D. Kleinhenz, J.C. Scheerens, and P.P. Ling. 2007. Anthocyanin levels in nine lettuce (Lactuca sativa) cultivars: Influence of planting date and relations among analytic, instrumented, and visual assessments of color. HortScience 42:232-238.

Hance, P., Y. Martin, J. Vasseur, J.L. Hilbert, and F. Trotin. 2007. Quantification of chicory root bitterness by an ELISA for 11 beta,13dihydrolactucin. Food Chem. 105:742-748.

Lee, J.G., B.Y. Lee, and H.J. Lee. 2006. Accumulation of phytotoxic organic acids in reused nutrient solution during hydroponic cultivation of lettuce (Lactuca sativa L.). Sci. Hort. 110:119-128.

Mansfeld, R. 2008. Mansfeld's World Database of Agricultural and Horticultural Crops. 10 Sept. 2008. <http://mansfeld.ipk-gatersleben.de/>.

Park, K.W. and J.M. Lee. 2006. Wrap-ups: A unique method of vegetable usage and con- sumption in Korea. Chronica Hort. 46: 13-15.

Peirce, L.C. 1986. Vegetables: Characteristics, production, and marketing. John Wiley and Sons, Inc., New York, NY.

Peters, A.M., N. Haagsma, and A. van Amerongen. 1997. A pilot study on the effects of cultivation conditions of chicory (Cichoruium intybus L) roots on the levels of sesquiterpene lactones in chicons. Food Res. Technol. 205:143-147.

Price, K.R., M.S. Dupont, R. Shepherd, H.W.S. Chan, and G.R. Fenwick. 1990. Relationship between the chemical and sensory properties of exotic salad crops-colored lettuce (Lactuca sativa) and chicory (Cichorium intybus). J. Sci. Food Agr. 53:185-192.

Rees, S.B. and J.B. Harborne. 1985. The role of sesquiterpene lactones and phenolics in the chemical defense of the chicory plant. Phytochem. 24:2225-2231.

Reineccius, G. 2006. Flavor chemistry and technology. 2nd Ed. Taylor \& Francis, Boca Raton, FL.

Song, Q., M.L. Gomez-Barrios, E.L. Hopper, M.W. Hjortso, and N.H. Fischer. 1995. Biosynthetic studies of lactucin derivatives in hairy root cultures of Lactuca floridana. Phytochem. 40:1659-1665.

Tamaki, H., R.W. Robinson, J.L. Anderson, and G.S. Stoewsand. 1995. Sesquiterpene lactones in virus-resistant lettuce. J. Agr. Food Chem. 43:6-8.

Van Beek, T.A., P. Maas, B.M. King, E. Leclercq, A.G.J. Voragen, and A. Groot. 1990. Bitter sesquiterpene lactones form chicory roots. J. Agr. Food Chem. 38:1035-1038.

Yamazaki, K. 1982. Nutrient solution culture [in Japanese]. Pak-kyo Co., Tokyo, Japan. 